\title{
Papers
}

\section{Cross sectional, community based study of care of newborn infants in Nepal}

\author{
David Osrin, Kirti M Tumbahangphe, Dej Shrestha, Natasha Mesko, Bhim P Shrestha, \\ Madan K Manandhar, Hilary Standing, Dharma S Manandhar, Anthony M de L Costello
}

\begin{abstract}
Objective To determine home based newborn care practices in rural Nepal in order to inform strategies to improve neonatal outcome.

Design Cross sectional, retrospective study using structured interviews.

Setting Makwanpur district, Nepal.

Participants 5411 married women aged 15 to 49 years who had given birth to a live baby in the past year.

Main outcome measures Attendance at delivery, hygiene, thermal care, and early feeding practices. Results 4893 (90\%) women gave birth at home. Attendance at delivery by skilled government health workers was low $(334,6 \%)$, as was attendance by traditional birth attendants $(267,5 \%)$. Only $461(8 \%)$ women had used a clean home delivery kit, and about half of attendants had washed their hands. Only 3482 $(64 \%)$ newborn infants had been wrapped within half an hour of birth, and 4992 (92\%) had been bathed within the first hour. 99\% (5362) of babies were breast fed, 91\% (4939) within six hours of birth. Practices with respect to colostrum and prelacteals were not a cause for anxiety.

Conclusions Health promotion interventions most likely to improve newborn health in this setting include increasing attendance at delivery by skilled service providers, improving information for families about basic perinatal care, promotion of clean delivery practices, early cord cutting and wrapping of the baby, and avoidance of early bathing.
\end{abstract}

\section{Introduction}

Although infant mortality has fallen in many developing countries over the past two decades, the rate of fall may be slowing. ${ }^{1}$ One reason is the resistant contribution of neonatal mortality, which has remained fairly steady over this period..$^{2}$ For many mothers, health care during and after childbirth is virtually nonexistent, and in 2000, an estimated 53 million women in developing countries gave birth without professional help. ${ }^{4}$

The World Health Organization guidelines for essential newborn care encompass cleanliness, thermal protection, initiation of breathing, early and exclusive breast feeding, eye care, immunisation, management of illness, and the care of low birthweight infants. ${ }^{5}$ For a mother and her family, this means preparing for birth, choosing a safe place for delivery, keeping the process clean, avoiding the cold, breast feeding early and exclusively, and understanding (and reacting to) potential danger signs. Our understanding of what happens at home and how to change behaviour is limited.

We are conducting a cluster randomised controlled trial on the effect of a community based participatory intervention to improve essential newborn care in Nepal. The trial involves 170000 rural people in 12 pairs of village development committees in Makwanpur district. The aim of the present study was to describe newborn care practices quantitatively in the cohort of women recruited to the trial.

\section{Participants and methods}

\section{Setting}

Nepal has a population of 23.4 million with more than 60 ethnic groups. The landscape tiers down from the Himalayas, through middle hills, to plains in the south. The population is poor, and there are limited communications and infrastructure. The gross national product per head is about $\$ 220(£ 145, € 223){ }^{7}$ the human development index is $0.378,{ }^{8}$ life expectancy is 58 years, about $60 \%$ of adults are illiterate, ${ }^{7}$ the total fertility rate is 4.8 in rural areas, and early marriage and adolescent pregnancy are common. ${ }^{9}$

Nepal's estimated neonatal mortality rate is $50 / 1000$ live births and accounts for two thirds of the infant mortality rate $(79 / 1000))^{9}$ Less than half of pregnant women attend for any antenatal care, ${ }^{9-13}$ and over $90 \%$ of births occur at home. ${ }^{9}$ After marriage, women usually move into their husband's family home and their mother-in-law becomes the central female figures in their lives. They give birth at home in the company of female friends and family, and their mother-in-law often takes the lead in advising on birth, childcare, illness, and when and where to seek professional help.

Nepal introduced integrated primary health care in the late 1970 s, with tertiary hospitals at the centre, zonal and district hospitals in the periphery, and a hierarchy of primary health centres, health posts, and subhealth posts in the community. The system suffers from unfilled posts, absenteeism, shortfalls in equip-
International
Perinatal Care Unit,
Institute of Child
Health, University
College London,
London
WC1N 1EH
David Osrin
clinical research fellow
Natasha Mesko
research fellow
Anthony M de L
Costello
professor
Mother Infant
Research Activities,
GPO Box 921,
Kathmandu, Nepal
Kirti M
Tumbahangphe
senior monitoring and
surveillance officer
Dej Shrestha
senior data
management officer
Bhim P Shrestha
programme manager
Dharma S
Manandhar
director
Nepal
Administrative Staff
College,
Kathmandu, Nepal
Madan K
Manandhar
director, centre for
local governance
Institute of
Development
Studies, Falmer,
Sussex BN1 9RH
Hilary Standing
research fellow, health
and social change
unit
Correspondence to:
A M de L Costello
ipu@ich.ucl.ac.uk 
ment and drugs, limited support to community based staff, and a lack of refresher training. ${ }^{14}$

\section{Makwanpur district}

Makwanpur district lies to the south of Kathmandu and has a population of nearly 400000 . It covers an area of $2500 \mathrm{~km}^{2}$ and includes both hills and plains. Over much of the district access is difficult and villages are widely spread. Most residents are engaged in small scale agriculture. There are at least 15 ethnic groups, the largest of which is Tamang (a predominantly Buddhist, Tibeto-Burman group), followed by Brahmin and Chhetri (groups of Indo-Aryan origin).

The district is geopolitically divided into 43 village development committees. Each committee has one government health institution (subhealth post, health post, or primary health centre). Perinatal care is provided from these facilities and the district hospital as well as by traditional birth attendants. Both service provision and uptake are patchy.

\section{Study design}

We conducted a cross sectional, descriptive study to collect information about most recent deliveries for women in Nepal. Married women of reproductive age (between 15 and 49 completed years on 15 June 2000) were eligible to enter a closed cohort. Chairs of the village development committees provided signed consent and all participants provided verbal consent to involvement. The study received ethical clearance from the Nepal Health Research Council, from His Majesty's Government Ministry of Health, Nepal, and from the ethics committee of the Institute of Child Health and Great Ormond Street Hospital for Sick Children, London.

We identified and mapped 28376 households between September 1999 and June 2000. Each married woman of reproductive age was allocated a unique identification number and visited by the field team to complete an individual questionnaire, including questions about newborn care during any preceding birth. The questionnaire was developed over 18 months through 11 cycles of piloting, evaluation, and repeat piloting. Data were collected by 44 field interviewers between March and November 2001, supported by nine field coordinators and one senior officer. Questionnaires were checked and missed questions amended at source, at field centres, and at the central office. A tenth of interviews were observed by supervisory team members.

We entered data into a relational database management system in Microsoft SQL server 7.0, which also incorporated intrafield and interfield constraints. We examined frequencies and outliers through structured queries in the database environment. We also analysed proportions after exporting data to small Stata 5.0. We have rounded percentages to integers for presentation.

\section{Results}

We interviewed 25702 women, of whom 24295 had given birth at least once, 24244 to a live baby. Because of concerns about the validity of recall over longer periods and the likelihood that practices have changed over time, we limited our analysis to the 5411 live births within the year before the start of the study. The median age of respondents was 25.1 years (interquartile range 9.3 years).

\section{Skilled attendance at delivery}

In all, 4893 (90\%) of women gave birth at home, either inside or in the courtyard (table 1). The district hospital accounted for $251(5 \%)$ births. Six hundred and nineteen $(11 \%)$ women gave birth alone. When an attendant was present, she was usually a family member or neighbour $(4241,78 \%)$, particularly the woman's mother-in-law (2178, 40\%).

We grouped the birth attendants into skilled attendants (doctors, nurses, auxiliary nurse midwives, and health assistants), semiskilled (village health workers, maternal and child health workers, and female community health volunteers, who are not technically trained in delivery and newborn care), and traditional birth attendants (many of whom have received training in obstetric care). On this basis, skilled attendants covered $6 \%$ of births (334), semiskilled attendants covered less than 2\% (96), and traditional birth attendants covered $5 \%$ (267). The coverage of any technical attendant was $12 \%$ (651 births).

\section{Cleanliness and hygiene practices at childbirth}

We asked the 4792 mothers who had help at the birth whether helpers had washed their hands before the birth of the baby. In all, 2729 (55\%) women recalled that helpers had washed their hands, 1372 (28\%) recalled that they had not done so, and 691 (14\%) could not clearly remember. Clean home delivery kits are currently manufactured and distributed in Nepal. Each kit contains a plastic sheet, a clean razor blade, a cutting surface, soap, and cord ties. Every woman interviewed was shown such a kit: $461(8 \%)$ had used one for their last delivery, 631 (12\%) recognised the kit but had not used one, and 4319 (80\%) did not recognise it.

The umbilical cord was cut with a razor blade in $3017(56 \%)$ births (table 2), although in only 1787 $(33 \%)$ could the blade be reliably described as clean. A

Table 1 Place of birth and attendance at delivery for women having a live birth in past year

No $(\%)$ of women $(n=5411)$

\begin{tabular}{lc}
\hline Place of birth: & \\
\hline Inside home & $4352(80)$ \\
\hline Yard of home & $541(10)$ \\
\hline Hospital & $251(5)$ \\
\hline Shed, field, or workplace & $182(3)$ \\
\hline Private clinic & $12(0.2)$ \\
\hline Other & $73(1)$ \\
\hline Birth attendant ${ }^{\star}$ & \\
\hline Doctor & $84(2)$ \\
\hline Nurse & $240(4)$ \\
\hline Auxiliary nurse midwife & $50(1)$ \\
\hline Health assistant (or comparable) & $39(1)$ \\
\hline Trained traditional birth attendant & $212(4)$ \\
\hline Untrained traditional birth attendant & $56(1)$ \\
\hline Maternal and child health worker & $50(1)$ \\
\hline Village health worker & $8(0.1)$ \\
\hline Female community health volunteer & $40(1)$ \\
\hline Mother-in-law & $2178(40)$ \\
\hline Other family member & $2371(44)$ \\
\hline Neighbour & $1617(30)$ \\
\hline No attendant & $619(11)$ \\
\hline Other & $366(7)$ \\
\hline
\end{tabular}

*More than one attendant may have been present. 


\begin{tabular}{lc}
\hline Table 2 Hygiene practices at delivery & \\
& No (\%) of births ( $\mathbf{n}=\mathbf{5 4 1 1})$ \\
\hline Instrument used for cutting umbilical cord: & \\
\hline New or boiled blade & $1787(33)$ \\
\hline Sickle or wood knife & $1947(36)$ \\
\hline Old unboiled blade & $1230(23)$ \\
\hline Household knife & $314(6)$ \\
\hline Other & $44(1)$ \\
\hline Unknown & $89(2)$ \\
\hline Dressing applied to umbilical stump: & \\
\hline Nothing & $3970(73)$ \\
\hline Oil & $994(18)$ \\
\hline Disinfectant & $116(2)$ \\
\hline Turmeric & $9(0.2)$ \\
\hline Cloth & $15(0.3)$ \\
\hline Mud & $9(0.2)$ \\
\hline Other & $156(3)$ \\
\hline Unknown & $142(3)$ \\
\hline Cloth for wrapping the baby: & \\
\hline Old washed cloth & $3803(70)$ \\
\hline Old unwashed cloth & $1385(26)$ \\
\hline New washed cloth & $79(1)$ \\
\hline New unwashed cloth & $18(0.3)$ \\
\hline Unknown & $126(2)$ \\
\hline & \\
\hline
\end{tabular}

Table 3 Practices related to maintenance of the warm chain for newborn infants

No $(\%)$ of births $(\mathrm{n}=\mathbf{5} 511)$

\begin{tabular}{lc}
\hline Heating of birthplace: & \\
\hline None & $1182(22)$ \\
\hline Before birth & $546(10)$ \\
\hline After birth & $2831(52)$ \\
\hline Throughout & $852(16)$ \\
\hline Time to wrapping of baby: & \\
\hline$\leqslant 5 \mathrm{~min}$ & $240(4)$ \\
\hline$\leqslant 10 \mathrm{~min}$ & $672(12)$ \\
\hline$\leqslant 30 \mathrm{~min}$ & $3482(64)$ \\
\hline$\leqslant 1$ hour & $5102(94)$ \\
\hline$\leqslant 6$ hours & $5400(100)$ \\
\hline Time to bathing of baby: & \\
\hline$\leqslant 15 \mathrm{~min}$ & $1808(33)$ \\
\hline$\leqslant 30 \mathrm{~min}$ & $3904(72)$ \\
\hline$\leqslant 1$ hour & $4992(92)$ \\
\hline$\leqslant 6$ hours & $5361(99)$ \\
\hline
\end{tabular}

household sickle was used in about a third of births. Sickles are not generally sterilised by heat or other means for this purpose. Once the cord had been cut, the umbilical stump was usually left undressed (73\%). The most common application was oil (18\%). Nearly all newborn infants were wrapped in used pieces of cloth. In three quarters of cases the cloth had been washed and dried in advance (table 2).

\section{Thermal control}

Given that most births occurred at home, usually indoors, we asked about the use of a fire to heat the birth room. There was some form of heating in 3683 $(68 \%)$ rooms after the baby had been delivered (table $3)$, and in $1398(26 \%)$ rooms the fire was laid for the labour. The time taken to wrap the baby was prolonged. Only $3482(64 \%)$ had been wrapped within half an hour, rising to $5102(94 \%)$ within an hour. Almost all babies had been bathed within six hours of birth, three quarters within the first half hour, and 92\% (4992) within an hour (table 3).

\section{Breast feeding}

Ninety nine per cent (5362) of women had breast fed. A taste of clarified butter (ghee), sugar, or honey was sometimes given before feeding began (12\%), but $85 \%$ of women said that the first feed given to their newborn infants was breast milk (table 4). Breast feeding was started within an hour of birth for $63 \%$ and within six hours for $91 \%$. Breastfeeding rates were about $99 \%$ at one week. Colostrum was discarded before the first feed in 2416 cases (45\%); foremilk was discarded at every subsequent feed in 3696 (69\%).

\section{Ethnic group comparison}

The ethnic composition of respondents was Tamang 3825 (65\%), Brahmin or Chhetri 948 (17\%), other Tibeto-Burman groups $413(8 \%)$, and other artisanal groups $522(10 \%)$. Although the general findings were similar for all groups, there were some minor differences. Tamang people tended to be poorer, to be engaged in agriculture, and to live further away from amenities. Tamang women were more likely to give birth outdoors and to cut the cord with a sickle and less likely to be attended by a service provider. This was also true of artisanal castes. Newar and Brahmin or Chhetri groups tended to be better off. They were more likely to deliver at a hospital, to be attended by health service providers, and to use clean home delivery kits and clean blades. They were less likely to give birth alone. Two ethnic differences were striking: Brahmin and Chhetris were much more likely to give a taste of sweet food as the first feed (513/948 v 435/5563 others; risk ratio $15.4,95 \%$ confidence interval 1.6 to 1.9 ), whereas Tamangs and women from artisanal castes were more likely to discard first colostrum and subsequent foremilk (2969/4014 v 727/1348; risk ratio 1.4, 1.3 to1.4).

\section{Discussion}

Our study has shown that use of a skilled birth attendant and uptake of government primary care services for childbirth and newborn care are uncommon in rural Nepal, hygiene is often compromised, and traditional practices expose newborn infants to a risk of hypothermia. However, early breastfeeding rates are better than expected and colostrum is only partially discarded.

\begin{tabular}{l}
\hline Table 4 Type and timing of first feed \\
\begin{tabular}{lc} 
& No (\%) of infants ( $\mathbf{n}=\mathbf{5 4 1 1})$ \\
\hline Infant's first feed: & \\
\hline Mother's milk & $6601(85)$ \\
\hline Ghee, sugar, or honey & $670(12)$ \\
\hline Breastmilk from another woman & $30(1)$ \\
\hline Cows' or buffalos' milk & $19(0.4)$ \\
\hline Formula & $11(0.2)$ \\
\hline Oil & $8(0.1)$ \\
\hline Other & $22(0.4)$ \\
\hline Unknown & $50(1)$ \\
\hline Time to first breast feed: & $159(3)$ \\
\hline$\leqslant 15$ min & $950(18)$ \\
\hline$\leqslant 30$ min & $3403(63)$ \\
\hline$\leqslant 1$ hour & $4939(91)$ \\
\hline$\leqslant 6$ hours & $5017(93)$ \\
\hline$\leqslant 12$ hours & $5157(95)$ \\
\hline$\leqslant 24$ hours & $254(5)$ \\
\hline$>24$ hours or never
\end{tabular} \\
\hline
\end{tabular}


The interpretation and generalisability of the findings might be limited by recall bias. To avoid this, we confined our analysis to pregnancies that had occurred in the past year. There was, in fact, hardly any difference if the period was extended to three years. The findings are also consistent with those of qualitative research carried out in the same population. ${ }^{15}$

\section{Assistance with childbirth}

The high proportion of home births is consistent with the findings of previous studies. ${ }^{9}{ }^{10}$ We took care to establish that, in most cases, home meant a room in the house rather than an outside area or another construction such as a cattle shed, a confusion that has been highlighted previously. ${ }^{16} 17$ The status of a woman's mother-in-law means that she is the most likely person to help during pregnancy, labour, and the postpartum period.

Attendance by trained service providers was extremely limited for both skilled government health staff $(6 \%)$ and traditional birth attendants $(5 \%)$, confirming previous findings. ${ }^{9} 1012$ Maternal and child health workers, identified by policy makers as potential key attendants, were present at less than $1 \%$ of deliveries, and it will therefore be a huge task to increase their coverage. Likewise, the small proportion of births attended by traditional birth attendants implies that assumptions about indigenous practices may be optimistic. Efforts to work with mothers-in-law and other family members may yield higher dividends in the short term.

We should be aware that $11 \%$ of women gave birth alone. This echoes previous findings, ${ }^{9}$ highlights the gender inequity that underpins many discussions of health, and may imply that childbirth is of limited urgency within a range of family concerns. In the longer term, efforts to strengthen outreach midwifery services should be a major priority. This will require a change in investment policy for reproductive health services and, given low levels of attendance by skilled health staff, may require years of investment to reduce mortality at a population level.

\section{Hygiene and warmth}

Infection may account for up to $40 \%$ of neonatal mortality. ${ }^{18}$ Particular concerns at birth are a clean place; a clean surface; cleanliness of the hands of attendants; clean cord tying, cutting, and dressing; and clean and dry wrapping of the baby (also a factor in avoiding hypothermia). Only half the attendants were said to have washed their hands. Clean home delivery kits were unfamiliar to most mothers $(80 \%)$ and were used by only $8 \%$ (slightly higher than previously $\left.\operatorname{described}^{10}\right)$. The use of razor blades to cut the cord is positive, although their cleanliness was suspect in two thirds of cases. Similarly, it is encouraging that $73 \%$ of umbilical stumps were not dressed, a higher percentage than previously estimated. ${ }^{10}$ The means of cutting the cord may not be as important a risk factor for infection as the means of subsequent dressing. ${ }^{19}$

Neonatal hypothermia has been described in $\mathrm{Nepal}^{20}$ and is a focus for essential newborn care. ${ }^{21}$ The common view of pregnancy as a hot state and the postpartum period as a cold one ${ }^{22} 2315$ ensures that mothers and their babies are kept warm in the puerperium ${ }^{24}$; we found that $68 \%$ of rooms were heated after labour. Unfortunately, this is counterbalanced by the practice

\section{What is already known on this topic}

Most births in rural south Asia occur at home

Neonatal mortality has remained fairly constant in developing countries despite falling infant mortality

\section{What this paper adds}

Only $6 \%$ of births in rural Nepal took place in the presence of a skilled attendant

Cord cutting implements were often unclean and drying and wrapping of newborn infants was usually delayed

$99 \%$ of babies were breast fed, $92 \%$ of them within six hours of birth, and colostrum was generally given

Interventions need to focus on educating women about hygiene, encouraging early wrapping, and delaying bathing of newborn babies

of waiting for the placenta to deliver before cutting the umbilical cord and wrapping the baby ${ }^{15}$ and by the tendency to bathe the baby so soon after birth.

\section{Infant feeding}

One area where traditional practices seem healthy is breast feeding. Almost all mothers breast fed their infants and use of formula was minimal. Moreover, $63 \%$ of babies had been fed in the first hour, considerably more than the $16 \%$ described in another study. ${ }^{10}$ This positive finding has implications for nutrition, prevention of infection, and thermal control and should be supported wholeheartedly. Prelacteals were given to less than $15 \%$ of infants. Our qualitative work suggests that the usual practice is to give a taste of nonbreastmilk food on the end of a finger, and only once. About half of women who breast fed $(45 \%)$ discarded a substantial amount of colostrum before the first feed, and two thirds (69\%) expressed a little foremilk at every subsequent feed. Probably, these practices do not justify intervention in rural Nepal, although the prevalence of these practices may vary in other south Asian communities.

\section{Implications}

Our study has identified important information about newborn care practices in rural Nepal that will assist in planning health interventions to change behaviour. In terms of public health and population attributable risk, the findings suggest that some changes would be particularly beneficial. These include increasing skilled attendance at births, improving hygiene at delivery, reducing delays in wrapping the baby, and delaying bathing. Interventions to reduce the use of prelacteals and stop women discarding colostrum and foremilk are likely to have a smaller effect.

We thank the many individuals in Makwanpur district who gave their time generously and the field staff of the MIRA (Mother Infant Research Activities) Makwanpur team, without whom the study would have been impossible. We also thank the Makwanpur district development committee and the village development committee members for their active and continuing support; and the MIRA executive committee in Kathmandu. 
Contributors: DO wrote the first draft of the paper and contributed to the study design and collection of field data. KT, DS, and BS contributed to the study design, collection of field data and analysis, and criticised later drafts of the paper. NM contributed to the study design and analysis, and criticised later drafts of the paper. MM and HS contributed to the design of the study and criticised drafts of the paper. DM and AC contributed to the design of the study and supervision of the field programme, and criticised drafts of the paper. Ananta Manandhar and Ashish Shrestha designed the database and helped with the design of the data entry and analysis process. DO and AC will act as guarantors

Funding: British Government Department for International Development, Unicef Nepal, and the Division of Child and Adolescent Health, World Health Organization, Geneva.

Competing interests: None declared.

1 United Nations Children's Fund. Trends in childhood mortality in the developing world 1960-1996. New York: Unicef, 1999.

2 Bhave S. Trends in perinatal and neonatal mortality and morbidity in India. Indian Pediatr 1989;26:1094-9.

3 Claeson M, Bos E, Mawji T, Pathmanathan I. Reducing child mortality in India in the new millennium. Bull WHO 2000;78:1192-9.

4 United Nations Fund for Population Activities. The state of the world's population 2000: lives together, worlds apart. New York: UNFPA, 2000.

5 World Health Organization. Essential newborn care. Report of a technical working group (Trieste, 25-29 April 1994). Geneva: WHO, Division of Reproductive Health (Technical Support), 1996.

6 Central Bureau of Statistics. Statistical year book of Nepal 2001. Kathmandu: His Majesty's Government National Planning Commission Secretariat, 2001

7 World Bank. World development report 2002. Building institutions for markets. Washington, DC: Oxford University Press, 2002

8 Nepal South Asia Centre. Nepal human development report 1998 Kathmandu: Nepal South Asia Centre, 1998.

9 Pradhan A, Aryal R, Regmi G, Ban B, Govindasamy P. Nepal family health survey 1996. Kathmandu and Calverton: Ministry of Health, Nepal; New ERA; Macro International, 1997.

10 His Majesty's Government, Nepal. Further analysis report on antenatal, delivery, postnatal services, literacy and polio coverage. Nepal multiple indicator surveillance fifth cycle (March-May 1997). Kathmandu: National Planning Commission Secretariat, Central Bureau of Statistics, Unicef Nepal, 1998

11 His Majesty's Government, Nepal. Care during pregnancy and delivery: implications for protecting the health of mothers and their babies. Nepal multiple indicator surveillance fifth cycle (March-May 1997). Kathmandu: National Planning Commission Secretariat, Unicef Nepal, 1998.

12 Family Health Division. The contributions of trained TBAs in Nepal. Kathmandu: Family Health Division, Department of Health Services, His Majesty's Government, Nepal, Centre for Economic Development Admininistration, Kirtipur, 1998.

13 Department of Health Services. Annual report 2056/57 (1999/2000). Kathmandu: Department of Health Services, His Majesty's Government of Nepal, 2001.

14 Justice J. The invisible worker: the role of the peon in Nepal's health service. Soc Sci Med 1983; 17:967-70.

15 Tamang S, Mesko N, Shrestha B, Osrin D, Manandhar M, Standing H, et al. A qualitative description of perinatal care practices in Makwanpur district, Nepal. Contrib Nepalese Stud 2001;28:10-9.

16 Manandhar M. Birthing practices study. Remote area basic need project-Bajura. Kathmandu: CARE, Nepal, 1999.

17 Thapa N, Chongsuvivatwong V, Geater A, Ulstein M, Bechtel G. Infant death rates and animal-shed delivery in remote rural areas of Nepal. Soc Sci Med 2000;51:1447-56.

18 Bang A, Bang R, Baitule S, Deshmukh M, Reddy M. Burden of morbidities and the unmet need for health care in rural neonates-a prospective observational study in Gadchiroli, India. Indian Pediatr 2001;38:952-65.

19 Traverso H, Bennett J, Kahn A, Agha S, Rahim H, Kamil S, et al. Ghee applications to the umbilical cord: a risk factor for neonatal tetanus. Lancet 1989;: $486-8$.

20 Ellis M, Manandhar N, Shakya U, Manandhar D, Fawdry A, Costello AM de L. Postnatal hypothermia and cold stress among newborn infants in Nepal monitored by continuous ambulatory recording. Arch Dis Child Fetal Neonatal Ed 1996;75:F42-5.

21 World Health Organization. Thermal control of the newborn: a practical guide. Geneva: Maternal Health and Safe Motherhood Programme, Division of Family Health, WHO, 1993.

22 Goodburn E, Rukhsana G, Chowdhury M. Beliefs and practices regarding delivery and postpartum maternal morbidity in rural Bangladesh. Stud Fam Plann 1995;26:22-32.

23 Nichter M, Nichter M, eds. The ethnophysiology and folk dietetics of pregnancy: a case study from South India. Hum Organiz 1983;42:235-46.

24 Iyengar S, Bhakoo O. Prevention of neonatal hypothermia in Himalayan villages. Trop Geogr Med 1991;43:293-6.

(Accepted 28 June 2002) 